\title{
Plummer vinson syndrome in a 6 year old boy
}

\begin{abstract}
Plummer-Vinson syndrome (PVS) also known as Paterson-Kelly syndrome or sideropenic dysphagia. ${ }^{1}$ is characterized by dysphagia, iron deficiency anemia and upper esophageal web(s). The most usual presenting symptom the dysphagia can be intermittent or progressive through the years. The dysphagia is limited to solids. Ever since it is reported, PVS is a disease of the middle-aged females and is very rare in children. ${ }^{2}$ Till date, to our knowledge, nine cases of PVS in children and adolescents only has been reported in the English literature. ${ }^{3-6}$ Here we report a case of Plummer Vinson Syndrome in a six year old boy.
\end{abstract}

Keywords: plummer vinson syndrome, dysphagia, anemia, esophageal web, pediatric age
Volume 9 Issue I - 2018

Rooby Erachamveettil Hamza, Nimiya Sabu M, Basim Ali, Faseela Kodithodi, Mashhood PadincharepurathuVillyoth, Mansoor C Abdulla

MES Academy of Medical Science, India

Correspondence: Rooby Erachamveettil Hamza,Assistant Professor, Department of Medical Gastroenterology, MES Medical college, Perinthalmanna, Kerala, Tel +91 9946847776, Email roobyshaheer@gmail.com

Received: August 05, 2017| Published: January 09, 2018

\section{Case report}

A 6year old boy presented with fatigue and progressive dysphagia for 4years. Dysphagia was concised to solid foods and took longer time to swallow even soft foods compared to his siblings. On examination his nutritional status was poor, he had grade II protein energy malnutrition (Figure 1), grade II stunting, severe pallor and angular stomatitis (Figure 2).

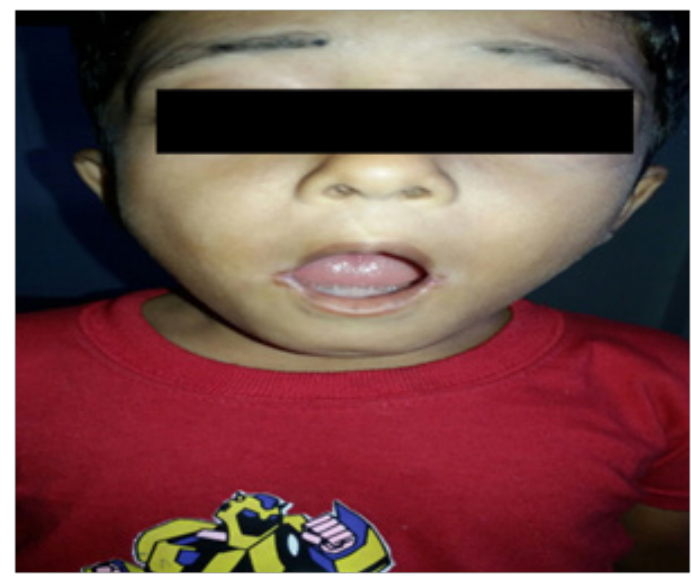

Figure I Nutritional status of protein energy malnutrition.

The investigations showed hemoglobin level of $8.7 \mathrm{~g} / \mathrm{dl}$ (microcytic hypochromic), total white blood cell of 13300 cells/cum and a platelet count of 5.1lakh/cumm. The work up for anemia revealed very low serum ferritin levels $(4.72 \mathrm{ng} / \mathrm{ml})$, high total iron binding capacity and low transferin saturation, consistent with iron deficiency anemia. Stool routine examination showed ova of Ancylostoma duodenalis. Other biochemical parameters were within normal limits. The esophagogastroscopy showed a web in the cervical esophagus (Figure $3)$. The web was ruptured with the scope afterwhich, the endoscope could be passed to the distal esophagus. Stomach as well as first and second part of duodenum appeared normal except for pale mucosa. He was started on albendazole and oral iron therapy with elemental iron $6 \mathrm{mg} / \mathrm{kg}$ daily. When reviewed after three months his general condition had improved and the repeat hemoglobin was $11.2 \mathrm{~g} / \mathrm{dl}$.



Figure 2 Pallor and angular stomatitis.

\section{Discussion}

The most common clinical features of the PVS are esophageal web(s) occurring commonly between upper and middle esophagus, dysphagia and iron deficiency anemia. ${ }^{1}$ Middle-aged women form the most affected patients and is supposed to be due to blood loss from menstruation and following pregnancies. ${ }^{2}$ Exact data about the incidence or prevalence of this syndrome do not exist yet; case reports published in the literature are the only source of information. Childhood cases are very rarely seen..$^{3-5}$

Anemia causing pallor, fatigue and weakness are the most dominating feature in the clinical picture of PVS, as we saw in our case. It was associated with dysphagia for four years. A fully explained pathogenesis of the syndrome is not yet understood, but to the far known facts, iron deficiency is the most probable mechanism. ${ }^{6}$ The additive factors include genetic predisposition, malnutrition and autoimmunity, but not yet proven with its role in pathogenesis of the syndrome. Consideration of these factors as a cause is due reports that suggest the coexistence of PVS with celiac disease, thyroid disease and rheumatoid arthritis. ${ }^{1,7,8}$ As theory suggest due to high cell turnover there is rapid losses of iron - dependent enzymes, which in turn usually cause the iron deficiency. A fall in these enzymes can lead to mucosal degenerations, atrophic changes in mucosa and web formation and may even cause upper gastrointestinal tract 
malignancies. ${ }^{5}$ Motility impairment due to decreased contraction amplitude of the esophageal muscle can be caused by iron deficiency. ${ }^{9}$ In a report by Miranda \& Dantas ${ }^{10}$ explains that compared to normal volunteers iron deficiency anemic patients had prolonged esophageal transit time in the esophagus. It was pronounced in upper $\&$ the middle segments while insignificant in distal parts. This forms an acceptable theoretic explanation for the occurrence of webs more common in upper parts.

Our case gives the awareness to look for the possibility of esophageal web in malnourished children with dysphagia which is usually underdiagnosed. The anemia in children and adolescents is thought to be caused due to sudden sprout of growth and increased erythropoietic activity in both genders while blood loss with menstruation hikes the incidence in females. In developing countries, infections also adds to effect like hookworms. In our case, it was mainly due to hook worm infestation, superadded with dietary deficiency, increased growth and lack of treatment in right time. In our country, although iron deficiency anemia is common, other reported case of PVS in childhood was hard to be found. ${ }^{2}$

\section{Acknowledgements}

None.

\section{Conflicts of Interest}

None.

\section{Disclosures}

\section{Conception and design}

Rooby Erachamveettil Hamza.

\section{Analysis and interpretation of the data}

Faseela Kodithodi

\section{Drafting of the article}

Nimiya Sabu, Mashhood PadincharepurathuVillyoth

\section{Critical revision of the article for important intellectual content}

Dr. Basim Ali, Mansoor C Abdulla

\section{Final approval of the article}

Rooby Erachamveettil Hamza.

\section{Funding}

None.

\section{References}

1. Novacek G. Plummer-Vinson syndrome. Orphanet. J Rare Dis. 2006;1:36.

2. Demirci F, Savaş MC, Kepkep N, et al. Plummer-Vinson syndrome and dilation therapy: a report of two cases. Turk $J$ Gastroenterol. 2005;16(4):224-227.

3. Crawfurd MD, Jacobs A, Murphy B, et al. Paterson-Kelly syndrome in adolescence: a report of five cases. Br Med J. 1965;1(5436):693-695.

4. Seitz ML, Sabatino D. Plummer-Vinson syndrome in an adolescent. $J$ Adolesc Health. 1991;12(3):279-281.

5. Lopez Rodriguez MJ, Robledo Andres P, Amarilla Jimenez A, et al. Sideropenic dysphagia in an adolescent. J Pediatr Gastroenterol Nutr. 2002;34(1):87-90.

6. Okamura H, Tsutsumi S, Inaki S, et al. Esophageal web in PlummerVinson syndrome. Laryngoscope. 1988;98(9):994-998.

7. Sood A, Midha V, Sood N, et al. Paterson Kelly syndrome in celiac disease. J Assoc Physicians India. 2005;53:991-992.

8. Medrano M. Dysphagia in a patient with rheumatoid arthritis and iron deficiency anemia. Med Gen Med. 2002;4(3):10.

9. Dantas RO, Villanova MG. Esophageal motility impairment in Plummer-Vinson syndrome. Correction by iron treatment Dig Dis Sci. 1993;38(5):968-971.

10. Miranda AL, Dantas RO. Esophageal contractions and oropharyngeal and esophageal transits in patients with iron deficiency anemia. Am J Gastroenterol. 2003.98(5):1000-1004. 